\title{
Pasifika education policy, research and voices: students on the road to tertiary success
}

\section{LEX MCDONALD AND TAVITA LIPINE}

\section{Abstract}

The literature indicates educational systems need to be responsive to the multiple worlds of minority students. Increasingly policies and strategies in New Zealand have been adopted to promote the development of Pasifika learners and in the tertiary setting, improvements have occurred, although more is needed. In the reported qualitative interview study, the voices of 36 Samoan high school students from 6 schools were analysed to identify factors considered important for academic success. Thematic analysis identified the passion to achieve, capacity to deal with inconsistencies, and the importance of a holistic orientation each resting upon a strong family orientation as being important. Recommendations arising from the study are outlined.

\section{Introduction}

$\longrightarrow$ or decades, ethnic minority educational under-achievement has $\longrightarrow$ been of concern in many contexts (Parker-Jenkins, Hewitt, 1 Brownhill, \& Sanders, 2007) - in the USA for Latinos, AfroAmericans and Indians (The College Board, 2010), in the UK for Caribbeans, Bangladeshis, Pakistanis and African Blacks (ParkerJenkins et al., 2007), and in Australia for Aborigines (Australian Bureau of Statistics, 2011). In New Zealand, the relative lack of educational performance of Pasifika ${ }^{1}$ students has been of concern.

\footnotetext{
1 Pasifika (sometimes spelt Pasefika) is the term used to describe Pacific Island migrants to New Zealand from Sāmoa, Tonga, the Cook Islands, Niue,
} 
Although many of these ethnic minority families have low incomes which is often related to under-performance (Simms, Fortuny, \& Henderson, 2009), it is acknowledged that the education system needs to be more responsive to the needs of these students, their families and culture (Richards, Brown, \& Forde, 2007). In other words, their worlds need to be understood. In a similar vein, Airini et al. (2010) outlined the importance of listening to Pasifika voices to gather new knowledge and understandings about educational attainment. Accordingly, in this paper, Pasifika education achievement data are presented, and the results of a small scale research project based upon the voices of one set of Pasifika students' perceptions about what motivated them to achieve are discussed.

In coming to some understanding about the issue, there is a range of perspectives that can inform understanding of achievement of minority groups in mainstream education. For example, the sociocultural, cultural capital, ecological and critical perspectives can provide differing perceptions of the phenomenon (Osborne, 2001), but there are also more specifically-oriented theories such as persistence theory (e.g., Tinto, 1975) which considers retention of university students. A particularly useful lens for examining Pasifika tertiary achievement in New Zealand, as it accommodates the move towards a multi-cultural society, is the transitions the students make that are related to educational achievement. The New Zealand Ministry of Education (2009) notes, for example:

Pasifika people have multiple world views and diverse cultural identities. They are able to operate and negotiate successfully through spiritual, social, political, cultural and economic worlds. Success in education requires harnessing Pasifika diversity within an enabling education system that works for young people, their families and communities. (p. 7)

Tokelau, Tuvalu, and other smaller Pacific nations. Most of these Pacific nations were previously governed by New Zealand. Some, notably Niue and the Cook Islands, retain close administrative ties with New Zealand although they are now independent. Tokelau remains a dependent territory of New Zealand. 
This highlights the efficacy of the bridging multiple worlds' perspective developed by Phelan, Davidson, and Yu, (1991) which views a student's schooling as a pipeline moving from pre-school to university but larger numbers of ethnic minority and low-income students leaving prematurely. It emphasises, however, that diverse youth can 'beat the odds' in this pipeline as they move across the pathways of families, peers, schools and communities. Phelan et al. believe that a concerted effort by the key players in the system to act upon demographic, academic, vocational, community, family, challenges, resources and partnership issues could provide the means to facilitate improved development. The researchers identified a range of potential contexts describing the personal management of the borders of the two worlds, the implication being that plans for assistance need to reflect the differing situations. These borders consisted of the following: type I congruent worlds/smooth transitions; type II different worlds/border crossings managed; type III different worlds/border crossings difficult; type IV different worlds/border crossings resisted; type $\mathrm{V}$ congruent worlds/border crossings resisted; and type VI different worlds/smooth transitions. Although criticised (e.g., Varenne, 2000) on grounds that it overlooks interactive dimensions in the development of the management of borders (for example the role of the school's positioning), it is useful in that it highlights the importance of transitions from the participant's perspective and therefore promotes the importance of the learner's voice.

Border crossing is a phenomenon often discussed in terms of Pasifika educational achievement in New Zealand. Essentially, although the attainment levels are improving, it is still of relative concern compared to that of other ethnic groups. This sector of the population is young, fast growing and, while research has provided some answers to this group's educational problems, and policy implementation has made some positive differences, it is agreed (Chu, Glasgow, Rimoni, Hodis, \& Meyer, in preparation) that more research and understanding of Pasifika under-achievement is needed. Currently, one area of particular attention has been tertiary enrolment, retention and completion of studies, but there is a lack of data on the 
experiences of these students. However, one means of increasing understanding about experiences is to listen to the voices of students who can provide valuable insight into how to facilitate educational success. After considering the background issues of Pasifika students relating to research and policy in this paper, the perceptions of one group of successful senior high school (Samoan) students are outlined about their educational success. It is acknowledged that Pasifika students do differ (e.g., cultural-island orientations; New Zealand born or overseas born) but often they are in multiple worlds and need to transition effectively between the differing contexts, if educational success is to be achieved.

\section{Pasifika tertiary policy and research}

At the tertiary level, the government has a policy to increase the enrolment, retention and completion of studies for Pasifika students in an attempt to raise their qualifications and improve opportunities (Ministry of Education, 2012a), and tertiary providers are increasingly expanding and developing policies to achieve this goal. For example, in 2010 at Victoria University of Wellington, an Assistant Vice Chancellor (Pasifika) was appointed which was the first time a tertiary institution had created such a senior academic position for Pasifika. This office set in place strategies to encourage more Pasifika students to enrol in tertiary study and to identify the factors that acted as facilitators or barriers to study. An important development was the Pasifika Student Success Plan based on the findings of a qualitative research study (Toumu'a, 2011) that examined Pasifika student retention and completion. This study identified a range of factors that were related to students' ability to remain in study and persist, and highlighted a range of personal (e.g., attitudes), institutional (e.g., class size), and external (e.g., role of family) variables as being critical determinants of success. It also provided information about Pasifika students in university study and included a revised outreach plan, recruitment and enrolment processes, and improved student services and support, highlighted the importance of improving teaching and learning strategies, suggested staff development and capacity building opportunities, and identified financial assistance, campus and 
infrastructure rearrangements, and community engagement. Nevertheless, despite supports and services becoming increasingly available, the statistics indicate long-standing under-achievement with lower levels of achievement and completion rates remaining the lowest of any ethnic group in New Zealand (Ministry of Education, 2012b) despite the recent improvements in outcomes of post-graduate enrolments and improved participation, retention, and completion.

Given these concerns, the NZ Government's priorities for Pasifika tertiary education (Ministry of Education, 2012a) are clear: improve transitions from high schools, improve basic literacy, retain the students, increase achievement levels, increase the level of qualifications, and improve providers' efficiency, and strengthen research. Although, as indicated, considerably more research is needed, since the turn of the century there has been a flurry of research agendas and publications relating to Pasifika issues including teacher PD and teaching/learning strategies, and post-graduate thesis research. This additional high quality research is needed to provide understanding about how best to improve Pasifika students' academic outcomes, particularly to understand how to achieve high academic attainments (Chu, et al., in preparation).

To facilitate improvement, tertiary research and policy have emphasised development of participatory research strategies, effective teaching and learning processes, and improved qualification status (Airini et al., 2010; Anae, Coxon, Mara, Wendt-Samu, \& Finau, 2001; Ministry of Education, 2003a), and issues surrounding tertiary participation and qualifications have been explored by Anae, Anderson, Benseman, and Coxon (2002) and Wensvoort (2011a, 2011b). A range of effective tertiary training strategies in private training enterprises were detailed by Marshall, Baldwin, and Peach (2008), whilst Airini and Sauni (2004) identified in teacher education the importance of human rights in relation to factors such as personalpsychological, teaching, Pasifika support, peer assistance, and bilingual and student logistical considerations. Benseman, Coxon, Anderson, and Anae (2006), in a similar vein to Airini and Sauni, identified several factors to assist retention: personal, financial, support resources, family, peer, dedicated student space, Pasifika staff, 
and language use. Overall, however, according to Airini, et al. (2009), it is the teaching, as well as learner related factors and student services that determine Pasifika achievement. A tertiary student resource, 'Pasifika Journeys in Education' (Ministry of Education, 2003b), recommended that having friends, balancing commitments, maintaining health, making good career decisions and the development of academic skills would help the learner. Other studies have considered prerequisites for university study and have examined the improving rates of NCEA attainment (Ministry of Education, 2010), and there have been a number of studies with a broader coverage investigating Pasifika education and school improvement initiatives at the different levels of education (e.g., Amituanai-Toloa, et al., 2010; Coxon, Anae, Mara, Wendt-Samu, \& Finau, 2002; Ferguson, Gorinski, Wendt-Samu, \& Mara, 2008).

There are other research projects and commentaries that have considered Pasifika education and achievement in general (e.g., local regional reports, Education Review Office national reports) and these are also linked by this common understanding - although there is improvement in Pasifika educational status, there remains disparities in achievement. This was one of the reasons why the Starpath Project at the University of Auckland was developed. Established in 2004, it aimed to understand the comparatively high rate of educational inequality for Māori, Pasifika and low socio-economic tertiary students, and then facilitate interventions. It has considered a raft of issues relating to transition, navigation of NCEA choices, student persistence, academic counselling, demographic factors (especially socio-economic status, ethnicity and number of students enrolled at Year 13) impacting on university entrance success rates, the effect of a criterion-based university entrance process, and the range of achievement standards available to students in a school. Starpath's extensive report The Starpath project: Partnership for excellence (University of Auckland) ${ }^{2}$ indicates that more is needed to facilitate the educational success of Pasifika students.

${ }^{2}$ http://www.education.auckland.ac.nz/uoa/home/about/research/starpath-home/ 
The Ministry of Education Pasifika Education Plans, developed since the turn of the century, have successively outlined the importance of improved achievement but it was not until the Ministry of Education Monitoring Report 2009 (2010) that a graphic compass organiser was used to promote systematic research findings and processes. Five key levers to explore and understand educational achievement with regard to research were identified: governance and leadership, families and community engagement, literacy and numeracy, effective teaching, and transitions. Using these key research areas, Chu et al. (in preparation) are currently developing an analysis of recent Pasifika education research relating to improved learner outcomes, which builds on the work of Coxon et al. (2002) and locates evidence to support policy and practice and indicates the significant information gaps and research priorities that persist. Key issues relating to effective teaching and learning, bilingualism, community involvement, transitions, culturally responsive teaching/assessment, student subject choices, student-teacher relationships, student motivation, barriers and challenges in higher education and tertiary student learning profiles are detailed as needing further research so that Pasifika educational strategies are well informed.

While more research is required to inform improved outcomes, some issues limit the applicability of the findings. For example, participants are often described as 'Pasifika' but there is a myriad of different Pasifika groups, each with unique qualities. Furthermore, the research is often small scale, non-longitudinal and qualitative with some studies lacking an empirical basis (Chu, et al., in preparation), and validated measures are not always present, making findings questionable. In addition to this, there is a compounding problem lack of research funding; sources of funding are currently limited to Government grants. Hence, there is a need for more rigorous research to provide data that are valid, more intense, relevant, and meaningful to implement a constructive policy.

Although research protocols, knowledge, and policies concerning Pasifika (e.g., Airini, et al., 2010) have been at a formative stage, the existing research and policy understandings can provide a framework 
for investigations. For example, reference is made to the importance of inclusion of Pasifika research personnel, and the voices of Pasifika participants to ascertain their experiences and perceptions. Listening to the voices of Pasifika students utilises a rich commanding methodological approach that can provide valid knowledge for authorities to facilitate improved learning outcomes. As an example, in the following study (Lipine, 2010), successful Samoan high school students provide their perceptions of what promoted their educational success. This research is important because it gathers information from a group of academically successful Pasifika students who were, in the main, planning to move into tertiary education.

\section{Successful Samoan high school students}

\section{Study context}

Lipine's (2010) study aimed to identify the critical dimensions that make for successful achievement at school by a minority group. The specific research question was to gather Samoan senior high school students' perceptions about what motivated them to succeed academically in the education system. It was unique as it was based upon voices of the students who described the events, strategies, experiences and contexts that facilitated their academic achievement. It highlighted what it means to be a member of a minority group in mainstream educational settings, the pervasiveness of cultural impacts, and located explanations for success and failure in educational achievement. An overall central focus of the findings was the importance of culture (in this case fa'asamoa - the Samoan way) which in a Pasifika context specifies behaviour, and specifically the obligations that an individual owes their family, community and church. This implies the participants' sense of identity and the respect that was due to others. It is important to note, however, that the findings reflect only one Pasifika group's views; other island groups may have differing viewpoints. 


\section{Study purpose and methodology}

The purpose of the phenomenologically-oriented study, undertaken in Auckland and Wellington, was to gather perceptions of what motivated Pasifika students to succeed. Although success at school can be widely interpreted, in this research, success was defined by academic achievement results, one of the important determinants for university entrance. The usual ethical guidelines of confidentiality, anonymity and informed consent were followed, and the process was consistent with recommended Pasifika research methodology with a Samoan researcher undertaking field work. Emphasis was placed upon researcher-participant relationship building, Pasifika student voices were gathered, consultation occurred with knowledgeable people about the Pasifika research context, the topic was investigated via a qualitative approach with semi-structured face-to-face interviews and focus groups, and food was given to the students in appreciation (Airini et al., 2010; Anae et al., 2001; Ministry of Education, 2012c). The principals of six schools identified high-achieving (voluntary) participants. Data were gathered from 36 year 12-13 students and the interviews were audio recorded for transcription and analysis. The data were thematically analysed as recommended by Miles and Huberman (1994) using an inductive process with identification of codes that were sorted into themes.

\section{Results}

There were four discernible interrelated patterns of response: learning impact factors, student learning preferences, personal-psychological qualities, and cultural factors. According to the students, these factors determined their academic success.

There was a range of factors related to learning impacts including perceptions about specific learning support factors and wider school associated support. Of particular importance to the students was both their teachers' understanding of their learning needs and their personal qualities:

Our teachers gave us more practical learning activities and many of my friends and I enjoyed that style. They do not use complicated 
English words.... They also asked many questions about topics to make us think.

At times I feel restless in the classroom....but my teachers used lots of funny examples and jokes to relate to the topic, which made me....willing to learn.

Some teachers encouraged the use of the Samoan language to support learning, and permitted the students to work together on tasks:

Every time I write an essay....I always refer to the Samoan structure....Sometimes I use a cross-cultural approach such as writing English essays using both English and Samoan ideas.

I reckon you learn in pairs but you'll learn more in a group where you share your opinions and understanding.

Academic success was not only related to the classroom learning context but a number of students noted the importance of activities and contextual issues external to the classroom, such as school trips, outdoor activities, and tutorial and other group-learning opportunities:

On various occasions my school visited other schools, churches and communities, which helped my schooling in terms of developing my communication skills and broadening my understanding.

Frequent reference was made to the academic and teaching reputation of the school and its available resources. Many viewed their school as an important part of their identity, which made them more determined to succeed, and engaging in school activities helped with decision-making, confidence and studying:

My school is like my family. If I do well,...achieving higher results in school examinations or winning sports, it means I am giving my school a good name. If I misbehave and fail examinations, I am letting my school down.

The school situation, location and population also provided another set of influences that motivated students. For example, the choice of a high achieving school (e.g., in terms of NCEA) and often the consequent cost of travelling to that school resulted in students' motivation to succeed to repay the family's investment. One student discussed the school location in relation to the visibility of professionals (for example, lawyers and business people in a central 
business district) whilst others were motivated to succeed by the perceived competition arising from interaction with other ethnic groups:

Being enrolled at a school in the city allowed me to learn and experience the town life-style. I have seen many people working in higher profile professions and that motivated me to succeed.

My school has many papalagi ${ }^{3}$ students which is good for me because it motivates....You know, being a brown skin in a white orientated school such as my school is not easy - some students expect you to come last....I do not want to come last.

The second major finding related to student learning preferences. As detailed previously, use of the Samoan language and working with peers were considered valuable ways to approach learning. Several students identified specific student learning approaches during the lesson as being very useful which included learning breaks, availability of food, drink and music while studying, individual and group work, library research, and opportunities to explore classroom displays. One student developed a sequence for engaging with new English words:

Practise makes perfect. To me it is a challenge when I come across new English terms that I do not understand. I write them down, and then look up in the dictionary when I study at home.

Another approach (consistent with fa'asamoa) was the value of listening to others, but interacting with them at a deeper level only if a trusted relationship had developed:

I do not like sharing my problems with other people such as those that I do not know. They might be thinking that I am stupid....I do not mind talking to the teachers as long as no-one else is listening.

The third major response identified with academic success was the personal and psychological qualities of the student. A wide range of factors was identified, but most centred around responsibility to others, prejudice reaction, and facilitative personal academic qualities (e.g., confidence) that promoted success. A particularly important

3

Papalagi is defined as non-Samoans especially people of European stock. 
energy was the sense of responsibility imbued in the students by family and community expectations.

I am aware that my family expects me to succeed because they believe I am the brightest.

Many people of my church see me as a potential university candidate. ...I hate failing because they will laugh at me and my family if that happens.

A somewhat curious finding was that some students were motivated to succeed because of the perceived negativism and prejudice of the papalagi students. To them it was a challenge to the Samoan cultural identity and students' pride, which necessitated a response.

I get angry about it but I do not use that anger in a violent way. I use prejudice to motivate me to work hard and be successful. There is nothing as powerful as being smart to silence the critics especially those who look down on us Samoans.

A range of specific personal academic qualities was also deemed to be important for success - in particular being considerate, confident, open, mature, aware, passionate, and having pride:

You've got to establish a culture for example - perseverance, enthusiasm, be hardworking - from the characteristics that you've already inherited to assist you.

I think maturity is also one of the characteristics.....If you are a person that has self-control you can do your work properly. You can also take on other responsibilities.

The fourth major finding related to a range of socio-cultural factors. The notion of just having others' support (apart from specific learning help) was particularly important, and friends and family were perceived to be especially valued in shaping students' success:

Being involved in a group of Samoan students, it helps you....They all understand because if one Samoan doesn't pass, the other Samoans don't say “I hate you” because they all understand and they are not gonna put you down. 
Being around with other family members is very important to me. It allows us to learn and understand each other. Having a close relationship with your family leads to their full support.

Church and religion featured strongly in the students' responses. They reported that the church played a significant part in their lives and helped them to achieve. Not only did it provide very practical support such as homework centres and counselling, but their faith also gave students the strength and discipline to succeed:

My church has been very supportive....It has established learning centres....I am a shy person but since joining these groups, I have become more confident.

These commitments have reminded me that I can achieve the best result through faith in God. I prayed to him to give me the strength and enthusiasm to drive for a better future and he did.

Sunday school also assists our understanding of religion which is important for life - that is, we are taught that we are rewarded according to the effort we put in our work. It encourages us to work hard and be enthused in our schooling.

A range of specific cultural factors was identified as being directly or indirectly helpful for success. For example, group-oriented tasks and sporting activities were frequently discussed. Some students commented upon the normative control exercised by parents to maintain fa'aloalo (traditional Samoan respect) which was believed to ultimately improve a student's educational development. As one student noted:

According to the Samoan culture you get the strap from your parents if you misbehave repeatedly...they want you to live a better life. When you get older you will learn more about respecting other people.

But it was also noted that traditional fa'asamoa could restrict development, and some believed changes were necessary if success was to be achieved. For example, some believed Western (palagi) approaches had some merit:

Palagi culture....influences my learning. While fa'asamoa is important to me, I prefer to use fa'apapalagi because it suits me. I guess I am lucky that I have the freedom to choose what's best for me. 
The communication style, which has a significant place in fa'asamoa, was identified as being important for learning. It was stated by a number of students that communicating in the fa'asamoa way was an essential skill for all to learn; when communicating with peers it was an interactive colloquial language but in communicating with adults there was a recognition of the importance of deference and rank balanced with an awareness of the importance of the individual's voice. A number of students noted the importance of interacting with the teacher:

It is very important that we have a consistent communication link with these teachers to maintain their understanding of what's relevant for our schooling.

Indeed maintenance of open and honest communication was perceived as important. A few students even indicated that disagreements with parents could be a positive phenomenon:

Sometimes I disagreed with my parents with regard to things....My parents respect me and they listen to me when I voice my opinions.

Monetary issues were also related to achieving success. Many Samoan families have a lower economic status which was reflected in the students' responses. One student typified this viewpoint when he stated:

I have been encouraged to work hard in my studies because I want to help my family's economic development. ....We believe successful achievement is the answer.

As noted, the results relate to four inter-related ideas: learning impact factors, student learning preferences, personal academic qualities, and specific culturally related characteristics. That is, learning was best supported if the class/school features adopted a cultural frame of reference as well as preferred personal learning opportunities. What was obvious, however, was that there was in each of the ideas a central importance attached to the over-riding influence of fa'asamoa and how it dictated the behaviour of the individual. It provided a clear outline of responsibilities and obligations to the family, friends, church, and community and this was functioning to 
safeguard the Samoan identity. It prescribed the framework of reciprocal structures that supported an individual's success.

\section{Discussion}

The results indicated a number of perceived 'bridges' or influences regarding educational success. Considered alongside the multiple worlds' perspective (Phelan et al., 1991) in which pathways to cross boundaries are emphasised, the framework outlined by Okagaki (2001) highlighted the importance of the schools, families, and identities in the process, and this provides a framework to interpret these findings. However, the stories told by the Samoan students indicated that it was more complex than this because there were inter-dependencies and local/regional issues to consider. For example, the interactions between these three dimensions were strong and uniquely influenced by a raft of important factors such as the power of fa'asamoa, bilingualism, specific teacher knowledge and behaviours, church responses, and the local social-economic forces needing to be considered.

A supportive school/teacher was regarded as important but there were indications that students actively sought and used support practices/processes themselves (e.g., peer support; using Samoan language to advantage). The students reported valued feelings of being included in the 'community of learners' and they sought meaning from the educators with a recognition of the conditions that promoted positive attitudes toward their learning.

The participants in the study identified the family and immediate contacts in the educational environment as a central support that was related to success but, in addition to this, there were strong interconnections with the wider community and agencies (e.g., church) and these all acted as a supportive 'suburban village'. Some of the students took a wider perspective and related their motivation to their associations with the more privileged students. This made an obvious comparison to the unequal economic position of their families, which then energised achievement motivation. An important function of the family was, however, to sustain as far as possible, the key elements of fa'asamoa; hence, it assumed a critical position in the normative development of Samoan student achievement. 
The third dimension of Okagaki's (2001) model, the maintenance of ethnic and academic identities, was evident but this also appeared to be a complicated inter-relationship. The Samoan students valued the role of fa'asamoa in their success and identity but this had to be accomplished with the changes occurring in the NZ context and linking this with the forming and maintenance of an academic identity. It was evident that the strong Samoan identity helped the learner to succeed in an educational environment characterised by the complexities of curricular modifications, teaching-learning changes, and 'competition' with other ethnic minorities. The bridge between the ethnic and academic identity was facilitated further by the personal and social qualities of the students and the support offered by others. It seems evident that the students managed their successes by membership of multiple worlds as exemplified by Phelan et al. (1991) type 2 (different worlds/border crossing managed) and/or type 6 (different worlds/smooth transitions) adolescents' worlds.

Weaving through these three dimensions were a number of themes (the passion to achieve, capacity to deal with inconsistency, and the importance of a holistic orientation) and a meta-theme (family or aiga functioning). Collectively, these themes provided meaning and understanding of participants' ideas and gave insight into their behaviours, beliefs, desires, and contexts for their educational experiences.

Passion to achieve significantly influenced the students. It was found that there was a range of factors influencing this passion such as personal/psychological (e.g., achievement attribution), social (e.g., family), educational (e.g., motivating learning techniques, teacher behaviours), cultural (e.g., use of Samoan language) and economic (e.g., wanting to improve the status of the family) issues. Central, however, was the desire to repay the family's sacrifices for students' education and this was based on the premise that education was the gateway to a better future for the student but also - and more importantly - for the family as well. Many of these features are discussed by Kessaris (2003) as contributing to minority group success. In terms of fa'asamoa, Tupuola (1996) noted that there are two fa'asamoa universals - alofa (love) and fa'aaloalo (respect) - 
which are significant unifying influences in dedication to study and schooling, and both these values imply supportive families and communities and obligations. But there was more to it than this - the data indicated a generalised passion about other aspects of the students' lives (e.g., church, sport, community). Taking pride and being proud is part of the Pasifika peoples' tradition (Hao'ofa, 2000) with functional and unique qualities (Hunkin, 1988). Traditionally, Samoans have had a socialisation that has emphasised that unity has a value, and success of others implies success for all, the implication being that Samoan students are likely to work to achieve higher academic grades for parents, relatives, and even their friends.

Another theme was the realisation that the students had to deal with inconsistencies in bridging the two worlds of the students. Foliaki (2001) noted that many Pasifika people born in NZ are influenced by contemporary ideas that impact upon traditional beliefs and behaviours but these have to be bridged because there remains an important attachment to Samoan cultural beliefs. The students acknowledged they were a diverse group and often differed in many ways to the dominant group characteristics - in their ethnicity, culture, religious commitment, socio-economic status, family characteristics, (etc). The circumstances of the students could have resulted in negative educational consequences, but because of their capacity to deal with inconsistencies in their worlds they were able to weave a successful path to ensure academic success. The students reported they adopted approaches and practices to deal with the varying circumstances they encountered in straddling the two sets of cultural demands.

The holistic orientation was another theme arising from the data. There was an emphasis upon maintaining the equilibrium of the mind, body, spirituality, family and environment as a whole and, according to Kingi-'Ulu'ave, Faleafa, and Brown (2007), this is an important framework in the Pasifika mindset to maintain stability. An essential aspect of this holistic orientation is the value of collectivism, which guides thinking and behaviour in daily life. These students clearly indicated that their upbringing within this collectivism framework was an important influence on achievement aspirations, despite the emphasis placed upon individual academic excellence that remains a 
priority in the NZ education system. To counter this, strategies (e.g., working with peers) were developed which maintained a fa'asamoa orientation. It was reported by a number of the students that those who were academically successful had families who were mostly able to accept some changes to fa'asamoa but did so in the absence of threat to the foundational and unifying value positions of an interdependent and holistically oriented way of life.

The passion to achieve, capacity to deal with inconsistency, and the holistic orientation were key themes that enveloped the results, but embracing these key ideas was a meta-theme. It was the functioning of the family that incorporated key fa'asamoa ideals in the individual, thereby assisting the participants to have the passion to achieve, deal with inconsistencies and then assume a holistic orientation. The family was perceived to be a central focus. A key concept was fa'aleaiga, a tradition where all family members must contribute to the well-being and development of aiga (Aiono 1996). Fa'aleaiga involves working together as a unit, sharing, and helping one another in terms of ideas, money, food, clothes, and beliefs. In essence, it was perceived by the participants as underpinning their success in the education system despite the evolution of Samoan family changes in NZ. For all the participants in the study, the parents (or other members of the aiga) had expectations, advice and understanding that became a driving force for the students' motivation to achieve.

A number of recommendations arose from this study. Firstly, the key stakeholders' views about what facilitated their development need to be considered in planning for student achievement. Secondly, bridging arrangements to assist the student need to be understood within a cultural context that has informed parents, peers and teachers acting in a concerted manner. Another important issue relates to teacher professional development - in a high school environment, in particular, the personal, social and cultural dimensions can be over-shadowed by attention to academic achievement. This is likely to be an ever greater problem when students are from a different culture. As indicated, however, by the Pasifika students, these are important dimensions that contributed to their educational success and accordingly, professional 
development programmes need to highlight the significance of these dimensions to teachers in the teaching-learning process.

\section{Conclusion}

Pasifika academic achievement is a continuing concern in New Zealand and there has been a noticeable increase in policies and understandings promoting achievement and research investigating the nature of the facilitative factors and barriers to improvement. For example, in the tertiary sector, there has been a move from deficit theorising to the development of contexts that promote and sustain improved achievement including an appreciation of the 'what' and 'how' of knowing and incorporating more culturally responsive pedagogical approaches. As evidenced by the research concerning successful Samoan high school student perceptions about success, it is likely that an integrated web of factors initiated early in a student's life will be part of the explanation of how educational success is best achieved. For these students, the compelling influences of fa'asamoa were evident and hence planning for ongoing educational success needs to be conscious of the role of the family, peers, community, language, religion, and underlying values of interaction.

‘Ua o le Malaga I Oloolo’ (We are on a mission and getting there).

\section{References}

Aiono, F. (1996). O Motugaafa. Apia, Samoa: Le Lamepa Press.

Airini, Anae, M., Mila-Schaaf, K. with Coxon, E., Mara, D., \& Sanga, K. (2010). Teu Le Va - Relationships across research and policy in Pasifika education: A collective approach to knowledge generation and policy development for action towards Pasifika education success. Auckland: UniServices.

Airini, Brown, D., Curtis, E., Johnson, O., Luatua, F., O’Shea, M., Ulugia-Pua., M. (2009). Success for all: Improving Māori and Pasifika student success in degree-level studies. Milestone report 8. Final Report. December 2009. Auckland, NZ: Uniservices.

Airini \& Sauni, P. (2004, July). Bring only the most beautiful: How human rights practices in adult education can help student success. Paper 
presented to the Learning and Teaching Together Conference UNESCO (NZ) and the NZ Human Rights Commission, Auckland, Aotearoa NZ.

Amituanai-Toloa, M., McNaughton, S., Lai, M., Airini, Turner, R., Widdowson, D., \& Pale, M. (2010). Ua aoina le manogi o le lolo: Pasifika schooling improvement research: Final report. Wellington, NZ: Ministry of Education.

Anae, M., Anderson, J., Benseman, J., \& Coxon, E. (2002). Pacific peoples and tertiary education: Issues of participation: Final report. Wellington, NZ: Ministry of Education.

Anae, M., Coxon, E., Mara, D., Wendt-Samu, T., \& Finau, C. (2001). Pasifika education research guidelines. Wellington, NZ: Ministry of Education.

Australian Bureau of Statistics. (2011). Australian social trends March 2011: Education and indigenous wellbeing. Canberra, ACT: Author.

Benseman, J., Coxon, E., Anderson, H., \& Anae, M. (2006). Retaining nontraditional students: Lessons learnt from Pasifika students in NZ. Higher Education Research \& Development, 25(2), 147-162.

Chu, C., Glasgow, A., Rimoni, F., Hodis, M., \& Meyer, L. (in preparation). An analysis of recent Pasifika education research literature to inform improved outcomes for Pasifika learners. Wellington, NZ: Ministry of Education.

Coxon, E., Anae, M., Mara, D., Samu-Wendt, T., \& Finau, C. (2002). Literature review on Pacific education issues. Wellington, NZ: Ministry of Education.

Ferguson, P., Gorinski, R., Wendt-Samu, T., \& Mara, D. (2008). Literature review on the experiences of Pasifika learners in the classroom. Wellington, NZ: Ministry of Education.

Foliaki, S. (2001). Pacific mental health services and workforce: Moving on the blueprint. Wellington, NZ: Mental Health Commission.

Hao'ofa, E. (2000). The ocean in us. In A. Hooper (Ed.), Culture and sustainable development in the Pacific (pp. 32-43). Melbourne, Australia: Asia Pacific Press.

Hunkin, G. (1988). Being Samoan means knowing my language. New Settlers and Multicultural Education Issues, 4(3), 28-35.

Kessaris, T. (2003). Minority group educational success: A review of research in the United States and Australia. In S. McGinty (Ed.), Sharing success: An indigenous perspective (pp. 146-168). Townsville, Qld: Common Ground.

Kingi-'Ulu’ave, D., Faleafa, M., \& Brown, T. (2007). A Pasifika perspective of psychology in Aotearoa. In M. Evans, J. Rucklidge, \& M. O’Driscoll (Eds.), Professional practice of psychology in Aotearoa NZ (pp. 67-84). Wellington, NZ: NZ Psychological Society. 
Lipine, T. (2010). Education of secondary Samoan students in New Zealand: The road to success. (Unpublished doctoral thesis). Victoria, University of Wellington, Wellington, New Zealand.

Marshall, J., Baldwin, K., \& Peach, R. (2008). Te rau awhina: Good practice examples of Māori and Pasifika private training establishments. Wellington, NZ: Ministry of Education.

Miles, M. B., \& Huberman, A. M. (1994). Qualitative data analysis. Thousand Oaks, CA: Sage.

Ministry of Education. (2003a). Pasifika education research toolkit. Wellington, NZ: Author.

Ministry of Education. (2003b). Pasifika journeys in education: A tertiary student resource. Wellington, NZ: Author.

Ministry of Education. (2009). Pasifika Education plan 2009-2012. Wellington, NZ: Author.

Ministry of Education. (2010). Participation and attainment of Pasifika students in National Certificate of Educational Achievement. Available at http://www.educationcounts.govt.nz/statistics/schooling/ncea-attainment/ participation-and-attainment-of-pasifika-students-in-national-certificateof-educational-achievement

Ministry of Education. (2012a). Tertiary education strategy 2010-15. Wellington, NZ: Author.

Ministry of Education. (2012b). Pasifika education plan monitoring report 2010. Wellington, NZ: Author.

Ministry of Education. (2012c). Pasifika education research priorities: Using research to realise our vision for Pasifika learners. Wellington, NZ: Author.

Okagaki, L. (2001). Triarchic model of minority children's school achievement. Educational Psychologist, 36(1), 9-20. doi:10.1207/S15326985EP3601_2

Osborne, B. (2001). An overview of research. Informing teaching students from different cultural backgrounds. In B. Osborne (Ed.), Teaching diversity and democracy (pp.1-50). Altona, Victoria, Australia: Common Ground.

Parker-Jenkins, M., Hewitt, D., Brownhill, S., \& Sanders, T. (2007). Aiming high: Raising the attainment of pupils from culturally diverse backgrounds. London: Sage.

Phelan, P., Davidson, A., \& Yu, H. (1991). Students' multiple worlds: Navigating the borders of family, peer, and school cultures. In P. Phelan \& A. Davidson (Eds.), Cultural diversity: Implications for education (pp. 52-88). New York: Teacher's College Press.

Richards, H., Brown, A., \& Forde, T. (2007). Addressing diversity in schools: Culturally responsive pedagogy. Teaching Exceptional Children. 39(3), 64-68. 
Simms M., Fortuny K., \& Henderson E. (2009). Racial and ethnic disparities among low-income families: Low-income working families fact sheet. Washington: Urban Institute.

The College Board. (2010). The educational crisis facing young men of color. New York: Author.

Tinto, V. (1975). Dropout from higher education: A theoretical synthesis of recent research. Review of Educational Research, 45(1), 89-125.

Toumu'a, R. (2011). Understanding the factors influencing Pasifika student retention and degree completion at Victoria University of Wellington. Wellington, NZ: Victoria University of Wellington.

Tupuola, S. (1996). Samoan traditional values and the changes. Wellington, NZ: Victoria University of Wellington.

Varenne, H. (2000). Adolescents in multi-ethnic schools: Turning borders into boundaries. APA Review of Books, 45(1), 43-45.

Wensvoort, M. (2011a). Pasifika in tertiary education in NZ: 2009. Wellington, NZ: Ministry of Education.

Wensvoort, M. (2011b). Pasifika tertiary students by ethnicity: 2009. Wellington, NZ: Ministry of Education.

\section{The authors}

Dr Lex McDonald is a senior lecturer and associate dean (academic) in the Faculty of Education at Victoria University of Wellington New Zealand. He has a background in teaching and the practice of psychology. Research interests include adult education, inclusive education, training of psychologists and teachers, Pasifika education issues and instructional psychology. Lex has numerous publications in the area of training, Pasifika education and culturally responsive teaching.

Email: lex.mcdonald@vuw.ac.nz

Dr Tavita Lipine is a lecturer in the Faculty of Education at the National University of Samoa (NUS). He trained as a teacher in New Zealand which subsequently led to research interests in cultural diversity in education, spirituality in church music, educational and cultural change in Samoa and ethnic minority educational issues. Involvement in sports also commands Tavita's time. Following the completion of his $\mathrm{PhD}$, Tavita has been involved in the preparation of a number of papers readying them for publication. 